\title{
LA ESTRATEGIA DE LA ATENCIÓN PRIMARIA \\ DE LA SALUD COMO OBJETO DE ESTUDIO \\ DE TERAPIA OCUPACIONAL
}

T.O. María CarlotaVega

Profesora Adjunta a cargo teóricos

Lic. en T.O. Emma García Cein

Jefa de Trabajos Prácticos.

Lic. en T.O. Maricel DonatI

Ayudante de Trabajos Prácticos.

Lic en T.O. Mariana Guaresti

Ayudante de Trabajos Prácticos

T.O. María Igriega

Ayudante de Trabajos Prácticos.

Cátedra: Terapia Ocupacional en Prevención Primaria y Comunidad.

Licenciatura en Terapia Ocupacional. Facultad de Ciencias de la Salud y Servicio Social. Universidad Nacional de Mar del Plata. Mar del Plata. Pcia. Buenos Aires. Argentina.

E-mailmcvega@copetel.com.ar

\section{Palabras claves}

Formación - Recursos Humanos - Atención Primaria Salud - Paradigma social en proceso Salud y enfermedad - Docencia en Terapia Ocupacional.

\section{Introducción}

La atención de la salud se ve influenciada por la calidad de la formación de sus recursos humanos, por esto, en la medida en que los futuros profesionales reciban una educación que permita ver al hombre como ser integral, se promoverá la unicidad y no la fragmentación que aleja el propósi- to de equidad que debe tener el sistema de salud.

A modo de antecedente, cabe señalar que en el año 1989, la Escuela de Ciencias de la Salud y del Comportamiento Humano, (hoy Facultad, de Ciencias de la Salud y Servicio So- 
cial), ante la necesidad de abrir nuevos campos para la práctica clínica de los alumnos de la carrera de Licenciatura en TO, plantea la apertura de un nuevo campo en salud mental, en un trabajo barrial. El mismo se orienta a la prevención primaria y se fundamenta en la estrategia de APS. Se sugiere la necesidad de que los alumnos reciban la formación académica para cumplir el rol que también desde la OMS, (1986) se estaba demandando desde una sociedad en continuo cambio.

\section{Objetivos}

Son propósitos de esta asignatura que el estudiante sitúe al hombre y a la mujer con relación a su salud desde una perspectiva social y de desarrollo humano, no sólo como individuo, sino en la comunidad o sociedad donde vive o desarrolla su potencial. Que reconozca, identifique y priorice sus necesidades, problemas, participación y, a partir del diagnóstico, pueda planificar, articulando recur- sos y evaluar los proyectos. Es imprescindible promover, en los alumnos, la mirada crítica y reflexiva, con el aval desde la teoría, de la realidad más cercana y del contexto del cual forman parte, todo ello con una fuerte presencia de la ética que se vea reflejada en el respeto por la comunidad y sus miembros, de su idiosincrasia y favoreciendo la horizontalidad y la participación.

\section{Metodología}

Es así como, desde hace más de una década, en el dictado de la carrera de Terapia Ocupacional los alumnos reciben tempranamente en su formación de grado un curso obligatorio y un seminario curricular dónde el rol y el trabajo del Terapeuta Ocupacional en el campo de Atención Primaria de la Salud en la comunidad es objeto de conocimiento valorado y comunicado como incumbencia profesional. Para intervenir desde un abordaje comunitario, se parte del concepto de salud desde un paradigma social, entendiendo a la salud, no sólo como la au- sencia de enfermedad, sino como la capacidad de lucha individual y social que tiene el individuo, para modificar las condiciones que limitan la vida. La participación comunitaria es un punto relevante en esta asignatura.

El conocimiento de la comunidad es fundamental ya que se considera a la salud como un proceso histórico, social y culturalmente determinado, relativo al estilo de vida y a la calidad de vida de los pueblos. Se promueve dicho conocimiento de la comunidad con visitas programadas a barrios perifé- 
ricos, entre otras técnicas de recolección de datos, de modo tal que el diagnóstico de la comunidad sea una realidad palpable y no solo de referencias indirectas.

En resumen es una meta proveer al alumno de situaciones que conlleven al conocimiento del hombre dentro de su comunidad, de sus estilos de vida y sus alternativas para acceder a los diferentes tipos de oportunidades (culturales, económicas, políticas, geográficas, espirituales...), en cada lugar y tiempo. Que pueda reconocer, identificar y priorizar las necesidades, y a partir del diagnóstico, planificar para intervenir eficazmente, articulando recursos y estrategias, y también evaluar dichos proyectos. Esta cátedra contribuye a la formación de una de las incumbencias de la Lic. en Terapia Ocupacional... "Participar en el planeamiento, ejecución y evaluación de planes, programas y proyectos destinados al diagnóstico, prevención y tratamiento de las enfermedades de la población".

Debido a lo cambiante de la realidad, es menester la plasticidad por parte de la cátedra para propiciar elementos que promuevan la adaptación activa del rol del Terapista Ocupacional en Prevención Primaria y Comunidad. En la sociedad se genera un contexto dinámico, de modo tal que en la medida en que van cambiando los problemas $y$ las necesidades de salud, que se ven expresadas en nuevos perfiles de morbilidad y mortalidad, también han de cambiar los servicios de salud y los abordajes en la comunidad, por esto también debe modificarse el perfil de los futuros profesionales que han de intervenir en esta realidad para mantener el circuito de calidad de la salud. Será necesario entonces promover flexibilidad y adecuación permanente para ser capaz de adaptarse a las necesidades cambiantes epidemiológico -sociales, facilitando tempranamente el conocimiento que jerarquiza este campo de desarrollo de la Terapia Ocupacional y ha permitido aumentar la calidad de formación de los recursos humanos en Terapia Ocupacional desde el paradigma social y conociendo la realidad en la que posteriormente se insertarán, promoviendo actores que propicien la Equidad y el derecho a la salud.

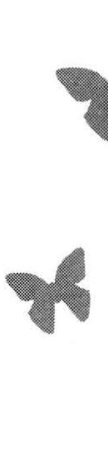

